\title{
Information Search, Alternatives Evaluation, and Coping Mechanisms of Functionally Illiterate Consumers in Retail Settings: A Developing Economy Context
}

\author{
Sisa Mhlanga and Theuns Kotzé \\ Department of Marketing Management, University of Pretoria, Pretoria, South Africa
}

\begin{abstract}
Little research has been carried out with regard to marketing to functionally illiterate consumers, despite the size and purchasing power of this market segment. This qualitative study examined the decision-making processes and coping mechanisms of functionally illiterate consumers in the South African grocery shopping environment. The findings provide insights that have important theoretical and practical implications for marketers, retailers, and policy makers. For functionally illiterate consumers, the information-search stage of the consumer decision-making process is either nonexistent or limited to a few trusted sources, such as friends and family, which often occurs only after a purchase has been made. Furthermore, these consumers face difficulties in a grocery store environment but have developed several coping mechanisms to compensate for their limited literacy skills.
\end{abstract}

Key words: adults, consumer behavior, decision making, functional illiteracy, grocery shopping

\section{INTRODUCTION}

The grocery shopping environment is becoming increasingly complex. Consequently, shoppers require high levels of literacy and numeracy to find their way through self-service displays, make sense of changes in product packaging, and correctly interpret price and product information. To navigate a supermarket successfully, consumers need to understand what they want to achieve and possess the necessary literacy skills to do so. It is estimated that 10 million South Africans lack the literacy skills they require to make informed purchase decisions. The absence of such skills creates significant challenges for consumers (Viswanathan, Rosa, \& Harris, 2005).

Several researchers have studied the behavior of functionally illiterate consumers in developed markets,

Address correspondence to Mr. Theuns Kotzé, Department of Marketing Management, University of Pretoria, Pretoria, 0002 South Africa. E-mail: tgkotze@gmail.com such as in the United States. The overall consensus of previous researchers is that functionally illiterate consumers encounter a range of challenges in the marketplace (Jae \& Delvecchio, 2004; Ozanne, Adkins, \& Sandlin, 2005; Viswanathan et al., 2005). These challenges range from choosing inappropriate products to misunderstanding pricing information and even failing to locate the required products in a store. Findings from previous studies reveal that functionally illiterate consumers develop specific coping mechanisms to manage the challenges they face in the shopping environment (Viswanathan et al., 2005). However, very little is known about how functionally illiterate consumers in developing countries cope with and manage their shopping experience in complex, sophisticated grocery shopping environments which require high literacy levels.

The main purpose of this study is to examine how functionally illiterate consumers in South Africa make decisions in order to accomplish shopping activities and to investigate the coping mechanisms they use while shopping in a supermarket. The typical consumer decision-making process consists of five stages. Once 
a problem is recognized, the consumer starts to search for information, then evaluates alternatives and makes a purchase; finally, the consumer evaluates the purchase and consumption experience (Schiffman, Hansen, \& Kanuk, 2011). The study specifically examines these issues in the context of grocery shopping. The research is based on semistructured interviews with adults attending a basic literacy training program. The findings reveal that functionally illiterate consumers face many difficulties in grocery stores. Based on these findings, guidelines are offered on how functionally illiterate South African consumers can be assisted to cope with and improve their shopping experiences and to guide policy makers in ensuring the well-being of these consumers.

Retailers in South Africa are faced with increasing costs. However, they attempt to decrease prices as they attempt to convince cash-strapped consumers to spend their income. Consumers in the meantime are finding their voices as social media platforms make it easy to compare products, prices, and experiences. The tasks facing retailers are numerous: they need to maintain service levels and still need to provide greater choice, demonstrate commitment to sustainability, and comply with increasingly difficult food labeling and employment equity legislation (Crosswaite, 2013).

The results of this research can make numerous contributions to government, marketing practitioners, as well as academicians. The results provide insight into the important issues facing illiterate consumers as well as how to protect the illiterate consumer. This will be important in both developing countries, where English is not the main language, as well as developed countries, where foreigners immigrate to either study or make a better life for themselves.

This article is organized as follows: First, literacy is defined and relevant theory regarding consumer decision making is introduced. Then, the methods used in this study are described, followed by a discussion of the findings. The article concludes with a discussion of the implications and limitations of this research project.

\section{LITERACY IN GROCERY SHOPPING}

\section{Defining Functional Illiteracy}

Literacy seems to be a simple term that everyone understands. However, literacy as a concept has proved to be both complex and dynamic (UNESCO, 2006). It is therefore difficult to arrive at a concise definition because of factors such as changing societal demands, inconsistent standards, and inadequate evaluation measures (Harrison-Walker, 1995). An assessment of the evolving definitions of literacy reveals that literacy is no longer absolute, where an individual is considered to be either literate or not. For the purposes of this study, literacy is not merely regarded as the act of reading and writing printed language. It is rather conceptualized as the ability to extract and process meaning in a specific social context (Fuat Firat, 2006). In this way, literacy is an active and creative process that allows individuals to participate in social and intellectual practices.

In economies where the typical consumer experience involves choosing from among differently priced products on shelf displays, the required literacy and numeracy competencies are relatively straightforward. These include the ability to read labels for product information, to navigate the complex retail environment by using store signage, to calculate unit prices and keep a running total; the latter to avoid being short of funds at the checkout counter (Gau \& Viswanathan, 2008). Limited literacy skills may impact negatively on consumers' ability to choose between similar product offerings, thus limiting their ability to compare available alternatives. For example, most packaging information is written in English, which is beyond the comprehension of many for whom English is a second language (Jae \& Delvecchio, 2004).

This study considers the competency of functionally illiterate consumers when engaging in grocery shopping and takes into consideration the possible challenges as well as the skills needed to function efficiently in this context. According to the South African Department of Education (2007), people are regarded as functionally illiterate if they dropped out of school before completing grade seven. This study thus defines functional illiteracy as the inability to use reading, writing, and numeracy skills to complete shopping tasks in a grocery store environment.

\section{Theoretical Perspectives on Consumer Decision Making}

A typical consumer decision process consists of five stages. The first is problem recognition, when a consumer realizes that a need requires satisfaction. Once a problem is recognized, the consumer starts to search for information, then evaluates alternatives and makes a purchase; finally, the consumer engages in a post purchase evaluation of the purchase and consumption experience (Schiffman et al., 2011). In this process, information search can range from a simple memory scan of previous situations to an extensive consultation involving the comparison of alternatives and resulting in a purchase. This article focuses on two stages of the consumer decision-making process, namely information search and the evaluation of alternatives.

The information processing strategies used by consumers to compare multiple product attributes and mentally eliminate product alternatives before choosing 
a preferred option are referred to as "consumer decision rules" (Kardes, Cline, Askegaard, \& Hogg, 2011). Consumer decision rules are either compensatory or noncompensatory. When following a compensatory decision rule, a consumer evaluates product options in terms of each relevant attribute by calculating a subjective score for each brand. This allows a positive evaluation of a brand on one attribute to make up for a negative evaluation on another attribute (Schiffman et al., 2011). For noncompensatory decision rules, consumers completely eliminate all alternatives that do not meet specific basic standards. To our knowledge, there is no formal theory of coping mechanisms for literate consumers in the field of consumer behavior.

\section{Information Search and Alternative Evaluations by Functionally Illiterate Consumers}

Research has shown that functionally illiterate consumers struggle with certain elements of the shopping environment such as product labels, store signs, and prices. Functionally illiterate consumers spend considerable energy and cognitive resources assessing value and making decisions based on information that literate consumers process automatically (Viswanathan et al., 2005). Jae and Delvecchio (2004) discovered that functionally illiterate consumers often make suboptimal product choices because of their overdependence on nonessential information in product advertising and on packaging.

Table 1 provides a summary of the findings about the challenges faced by functionally illiterate consumers. These challenges are grouped into two categories: challenges related to the store environment and product-related challenges. In this context, store environment challenges refer to those encountered in the broader retail setting, whereas product-related challenges relate to those associated with specific product choices.

TABLE 1

Challenges Experienced by Functionally Illiterate Consumers During Shopping

\begin{tabular}{ll}
\hline Store Environment Challenges & \multicolumn{1}{c}{ Product-Related Challenges } \\
\hline Abstract difficulties in the store & $\begin{array}{c}\text { Difficulties in processing numerical } \\
\text { product information } \\
\text { Locating prices }\end{array}$ \\
Store navigation & Reading numerical information \\
Reading signs & Computation \\
Information overload & Difficulties in processing text-based \\
Emotional aspects of the & product information \\
shopping experience & Purchase confusion \\
Distrust in buying & Recognizing terms \\
Experienced hostility & Misreading labels \\
Shopping with anxiety &
\end{tabular}

Source: Adapted from information found in Gau \& Viswanathan, 2008.
Challenges in the store environment include both abstract and emotional aspects. Abstract difficulties involve navigating and locating products in the store, reading signage, and processing written information. Functionally illiterate consumers depend heavily on assistance from retailers (Wallendorf, 2001) because they either fail to understand their own preferences or lack the knowledge and skills to act on them (Ringold, 2005). This results in emotional reactions such as anxiety and also exposes these consumers to hostility from store personnel (Gau \& Viswanathan, 2008).

Product-related challenges are caused by the inability to process textual and numerical information. The language on the packaging of frequently purchased, nondurable consumer goods is at a level beyond the comprehension of many functionally illiterate consumers, thereby making these consumers susceptible to risks associated with the improper use of products (Jae $\&$ Delvecchio, 2004). The illiterate consumer is not confined to a developed or developing country. This is as a result of immigrants. There are, for example, a number of immigrants in Canada and the United States whose native language is not English, leaving them struggling to understand product labels. South Africa has 11 official languages, and English is not the first language of the majority of South African consumers. Yet these consumers are expected to function in a predominantly English retail environment.

\section{The Coping Mechanisms Used by Functionally Illiterate Consumers}

Functionally illiterate consumers develop several coping mechanisms to assist in product selection. These mechanisms range from depending on others to ordering one item at a time off a menu. These consumers have a strong need to maintain self-esteem in public as they often do not want others to know that they are illiterate. Another coping mechanism used by illiterate consumers in an attempt to deal with their shortcomings is pattern matching (Viswanathan, Jung, Venugopal, Minefee, \& Jung, 2014).

In this context, coping mechanisms simply refer to methods or systems that functionally illiterate consumers use to overcome or compensate for the challenges encountered in the grocery shopping environment. Research has shown that functionally illiterate consumers incur different emotional and behavioral costs from shopping and that they display creativity in coping with such costs (Ozanne et al., 2005; Viswanathan et al., 2005).

Past research has revealed that functionally illiterate consumers use two major categories of coping mechanisms to meet their needs in the grocery store. The first category involves rejecting the stigma that is associated with being functionally illiterate. By rejecting the stigma, 
these consumers confront their challenges directly by relying on family and friends, as well as asking strangers for help. The second category involves directly avoiding the challenges of being functionally illiterate. By doing this, these consumers embrace the illiteracy stigma of feeling shame and inadequacy as they struggle silently and often unsuccessfully to locate products.

As mentioned before, previous studies on the coping mechanisms used by functionally illiterate consumers were done in developed countries. This calls for a study to investigate similar consumers in the South African grocery shopping environment.

\section{METHODOLOGY}

Several researchers have indicated that research among functionally illiterate consumers creates unique challenges (Adkins, 2001; Adkins \& Ozanne, 2005; Viswanathan et al., 2005). Functionally illiterate participants are often not in a position to complete standard research instruments such as survey questionnaires. Even if functionally illiterate respondents were to receive assistance, it is difficult to determine the measurement error attributed to the wide range of abilities found among functionally illiterate individuals (Viswanathan et al., 2005). Moreover, due to the stigma associated with illiteracy, many functionally illiterate individuals are not willing to openly discuss this topic (Adkins, 2001). However, as suggested by Adkins and Ozanne (2005), adults participating in literacy programs are more likely to share their experiences.

Given the inherent difficulties associated with identifying and studying functionally illiterate consumers, and following the approach used by Viswanathan et al. (2005), a purposeful sampling method was used to recruit participants at an adult literacy training centre in Pretoria, South Africa. As recommended by Sheth (quoted by Erasmus, Boshoff, \& Rousseau, 2001), the choice of qualitative research was intended to allow for the true experiences of these customers to unfold. Data were collected through semistructured, one-onone personal interviews with 12 individuals, as well as through one focus group session involving five of the informants who also participated in the individual interviews. The focus group was specifically used to further explore issues raised during the semistructured interviews. The participants were all enrolled for either Adult Basic Education Training (ABET) level one or level two on the basis of entry test scores in English and Mathematics. In South Africa, ABET level one is equivalent to grades one to three of primary school education, while level two is equivalent to grades four to seven. The participants ranged in age from 21 to 73 years.
Formal approval for data collection was obtained from the learning center management. The researchers then scheduled a meeting with the literacy tutors at the learning center. The main purpose of this meeting was to establish trust in order to overcome the sensitivity many functionally illiterate individuals have regarding their illiteracy. During the meeting, the researchers explained the objectives and relevance of the study. A second purpose of the meeting was to schedule interview appointments with prospective participants. All the candidates consented to take part in the study. To ensure anonymity, the participants were assigned pseudonyms that are used throughout this article.

\section{Data Collection}

Building on the data collection approaches used by Ozanne et al. (2005) and Viswanathan et al. (2005), an interview guide was developed. The semistructured interviews started with general questions meant to encourage participants to speak freely and to facilitate rapport. This was followed by questions directed at six photographs taken in a well-known South African supermarket outlet depicting different shopping scenarios to encourage participants to share their shopping experiences (see Appendix A). The participants were asked to tell a story about what they thought was taking place in each photograph. The first photograph showed a consumer studying a box of breakfast cereal. The second photograph showed a consumer and cashier interacting at a checkout counter. The third photograph showed a consumer and a pharmacist at a counter in a pharmacy. The fourth photograph showed two consumers talking and holding products in an aisle, with products on shelves in the background. The fifth photograph was of a consumer selecting a bottle of cooking oil. The sixth photograph showed a consumer looking at different brands of maize meal. Those photos were used as stimuli during the interviews. The purpose of this section was to explore participants' feelings and experiences in order to identify marketing mix elements that may lead to the use of different coping mechanisms. The rest of the interview was composed of semistructured questions on coping mechanisms identified from previous studies by Viswanathan et al. (2005) and Adkins (2001). Following the approach used by Ozanne et al. (2005), the purpose of this section was to explore feelings and experiences in order to identify how participants choose products. The semistructured interviews lasted between 30 and 60 minutes, depending on the receptiveness of each participant.

After completing all individual interviews, one focus group discussion was conducted to delve deeper into issues that came up during the semistructured interview sessions. The focus group discussion was based on a 


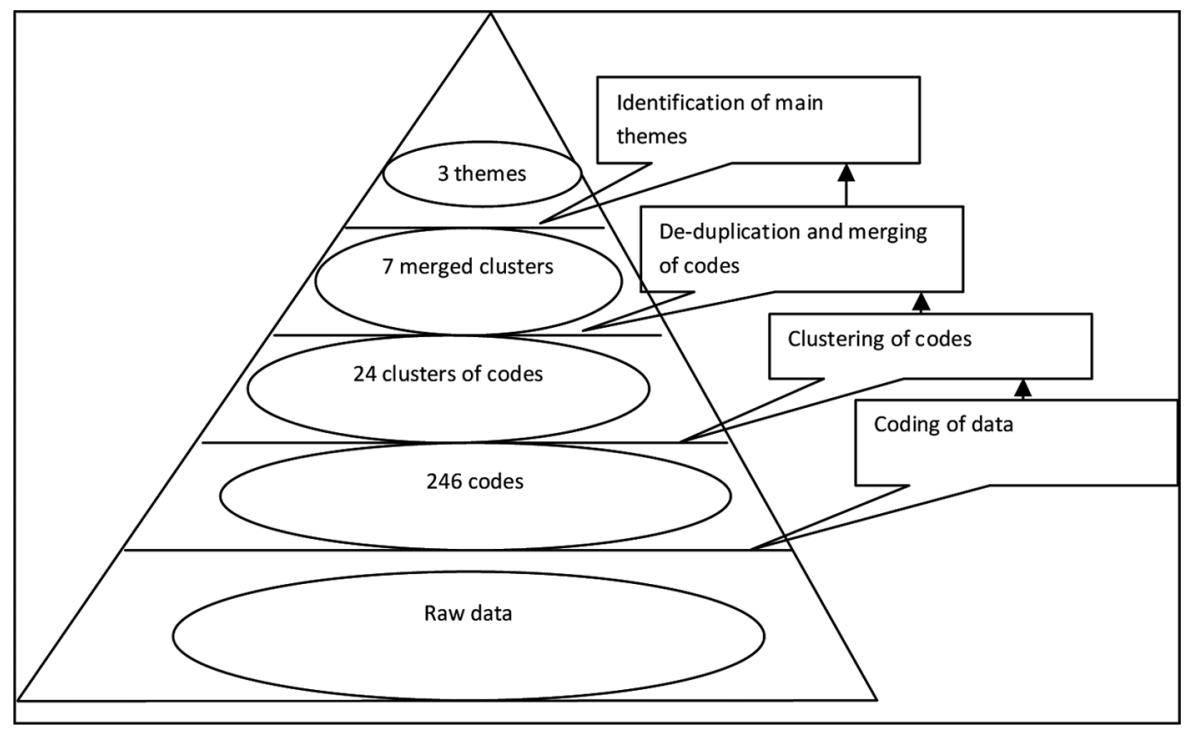

FIGURE 1 Schematic of Data Analysis Process Followed in the Study.

series of open-ended questions. The data collection was completed in two and a half months. The interviews were primarily conducted in either Sepedi or Zulu, two African languages spoken extensively in the Pretoria area. All interviews were recorded, translated into English, and then transcribed for analysis.

\section{Data Analysis}

Analysis of the data occurred through an iterative approach of moving back and forth between the data and previous studies to identify a logical chain of evidence and to find theoretical consistency. The original data was reread to assess and improve the evolving classification system. Throughout this iterative process of analysis and writing the findings, the primary data were continuously referred to in order to ensure the findings were accurately presented. The data focused on statements that shed light on how the participants process information, evaluate alternatives, make purchasing decisions, and cope with in-store challenges. A unit of data is meaningful if it is heuristic, revealing information relevant to the study and stimulating the researcher to think beyond that particular information (Merriam, 2009). Heuristic in this context refers to methods of solving problems by learning from past experience and investigating practical ways of finding a solution. The analysis process is presented in Figure 1.

To reduce the codes into meaningful themes, the researcher read through the 246 codes. These codes were

TABLE 2

Provisions Made to Ensure the Rigor and Trustworthiness of the Study Findings

Quality

Criterion

Credibility
Provision Made for this Study

Appropriate well-recognized research methods were adopted to collect the primary data.

Identification with the background of the participants was achieved by visiting the site before starting the data collection.

Triangulation was attained through the use of different data collection methods, namely semistructured individual interviews and a focus group.

Tactics to ensure integrity in the participants were implemented. This was achieved through including related questions that served as a check for consistency in responses to these related questions.

Iterative questioning was used in the data collection dialogue.

Examination of previous research to frame the findings.

Transferability Provision of background data to establish the context of study.

Description of the phenomenon in question was made to allow comparisons to be made.

Dependability Overlapping methods, namely semistructured individual interviews and a focus group, were employed.

Confirmability Triangulation was used to reduce the influence of investigator bias.

Recognition of the shortcomings in the study's methods was acknowledged.

In-depth methodological description was done to allow for the integrity of the research results to be scrutinized.

Use of diagrams to demonstrate audit trail was employed. 
compared and contrasted to identify similarities. Codes with clear connections were clustered. A total of 24 clustered codes emerged. These were assigned labels and displayed visually. The 24 clustered codes were labeled as Shoprite, dislike local shops, Pick n Pay, store layout, doctor/pharmacist, ask assistance (what), ask assistance (who), salespeople, store signs, finding products, literacy challenge, why enrolled, shop with others/alone, loves/likes shopping, bad experience, good shopping trip, packaging, brand, product attributes, new products, crime, checkout counter, money, and pricing.

Table 2 summarizes the provisions made to ensure the rigor and trustworthiness of this study.

\section{FINDINGS AND DISCUSSION}

In general, the findings of this study show that functionally illiterate consumers struggle to navigate a typical supermarket. They apply unique decision rules to guide their purchase decisions and have devised several coping mechanisms to deal with the challenges resulting from their low literacy levels. These aspects are discussed next.

\section{Decision Making by Functionally Illiterate Consumers}

The findings regarding decision making by functionally illiterate consumers can be split into two categories, namely decisions relating to store preference and decisions involving product choices.

\section{Decisions Relating to Store Preference}

Although the participants in this study patronized a limited number of local grocery stores, they displayed a strong preference for one particular large national grocery store chain. The interviews revealed that the store choice decision is primarily determined by the participants' comfort within the store environment. This is achieved when prices are perceived to be reasonable and especially when salespeople are seen as helpful.

\section{Decisions Involving Product Choices}

As mentioned earlier, consumer behavior theory suggests that consumers typically go through a series of decision stages before making a purchase. The data in this study, however, suggest that functionally illiterate consumers engage in few extended problem-solving decisions, thus validating the findings of Adkins (2001). These customers tend to choose products and brands out of habit. They are reluctant to try new offerings and would rather opt for familiar brands without attending to other product information. In addition, the findings indicate that functionally illiterate consumers engage in concrete reasoning, single attribute decision making and pictorial thinking when choosing between competing brands.

\section{Concrete Reasoning}

The information provided on product packaging is meant to inform consumers about the particular product. A product label typically contains information about the manufacturer, expiry date, directions for product use, net weight or volume, warnings about product misuse, and nutritional information (Prinsloo, van der Merwe, Bosman, \& Erasmus, 2012). However, the functionally illiterate participants in this study stated that they do not understand such information. Several of the participants only check the expiry date and disregard all other information provided on product packaging. These findings are consistent with previous research showing that price appears to be a central unit on which concrete operations are performed, while combining attribute information to generate value abstractions seems to be beyond the common practice of most functionally illiterate consumers (Viswanathan et al., 2005).

\section{Single Attribute Decisions}

Functionally illiterate consumers also tend to process single pieces of information such as price or single product ingredients while disregarding other product attributes and without deriving higher-level abstractions. Single attribute decisions are used as both a decisionmaking process and a coping mechanism (Viswanathan et al., 2005). During the interviews, it was, for example, discovered that the participants loosely use the word "vitamins" to refer to all forms of nutritional information.

\section{Pictorial Thinking}

At times, functionally illiterate consumers' decisions are directly linked to pictographic information provided on product packaging. Pictographic information refers to the visual images typically found on products in supermarkets, such as brand logos and packaging illustrations (Rosa, 2012). In some instances, functionally illiterate consumers use these visual cues to identify the specific brands that they wish to buy. Some consumers even regard these visuals as an indication of the quality of the product.

Changes to packaging seem to complicate decision making. When a product's packaging is changed, some of the participants may become skeptical about the quality of the product or even see it as a totally new 
product or brand. One participant, for example, knows the packaging of her favorite milk and emotionally relates to that brand. Although she does not know the brand name, she depends on the visuals on the packaging to identify the preferred brand.

\section{Coping Mechanisms Used by Functionally Illiterate Consumers}

Ordinary shopping tasks often create major challenges for functionally illiterate consumers. Given the many negative shopping experiences they have had to ensure, it is not surprising that these consumers have developed mechanisms that help them to cope with these challenges and negative experiences. This study identified 17 distinct coping mechanisms. These are described next.

\section{Memorizing}

The functionally illiterate participants in this study rely heavily on their memory to navigate complex shopping environments. They routinely memorize the layout of stores as well as visual cues on packages, such as brand logos and package designs and colors, to identify required products on store shelves.

\section{Shop at the Same Supermarket}

A familiar store layout not only saves time but also reduces the stress associated with an unfamiliar environment. For all participants, knowing the store layout makes shopping easier. By shopping at the same stores, functionally illiterate consumers become familiar with the store layout and with the location of desired merchandise.

\section{Go from Aisle to Aisle in the Store}

Most retailers periodically change the layout of their stores. Since some participants have developed the coping mechanism of memorizing the store layout, it is to their disadvantage when the store layout is changed. In response to this, some of the participants prefer to take their time to move from aisle to aisle in a store until they locate the products that they want.

\section{Do Not Shop where Salespeople are Unfriendly}

The participants displayed a general unwillingness to forgive retailers who cause them to have negative emotional experiences while shopping. As indicated by Viswanathan et al. (2005), functionally illiterate consumers are very sensitive to how they are treated by salespeople as this directly affects their self-esteem.

\section{Do without Items}

The findings confirm that some low literate consumers prefer not to ask for help and are determined to hide their poor literacy skills. They consequently struggle silently and would rather leave a store without the desired product. Adkins (2001) and Viswanathan et al. (2005) similarly found that functionally illiterate consumers often make conscious decisions to do without a desired product or to avoid certain marketplace environments.

\section{Pretend Disability}

Asking for help can reveal a consumer's illiteracy, hence these consumers admit to being uncomfortable asking for help because they are afraid to expose their limited literacy skills. Some of the participants used humor or deception (e.g., by feigning to be visually disabled) to hide their limited literacy skills.

\section{Buy Only Known Brands}

There is a general tendency among the participants to buy only known brands. This supports the findings by Adamowicz and Swaitare (2012) that most food products are chosen out of habit, with consumers opting for familiar brands without necessarily attending to other product information. Functionally illiterate consumers are generally risk averse and therefore have developed brand loyalty, preferring to buy known brands rather than to try unknown ones.

\section{Buy Retailer's Brand}

Retailer brands have come in handy in different situations. In instances when the participants have limited cash, they will substitute the brands they usually prefer with the retailer's brand because it is usually cheaper and also because "house brands" are often perceived as being of good quality.

\section{Use Single Attribute Decisions}

The participants used single attribute decisions to avoid stressful and complex product comparisons. To avoid comparing products on a number of attributes, the participants often use price as a guide when having to choose among competing brands.

\section{Avoiding Percentage Discounted Items}

Because they cannot easily interpret percentages, functional illiterate consumers are at a disadvantage when price discounts are expressed in percentage terms.

\section{Carry Extra Money to Avoid a Cash Shortfall}

Most of the participants have experienced cash shortfalls on occasion; hence they have devised a strategy of 
carrying extra money to ensure that they will not experience cash shortfalls when they have to pay. Most of the participants also operate on a cash-only basis and do not use credit or debit cards.

\section{Shop with Family Members and Friends}

Functionally illiterate consumers are highly conscious of their own vulnerability and of the negative emotions they would experience if their limited literacy skills are revealed to strangers. To protect themselves, they often ask for help from immediate family and close friends.

\section{Seek Help in Store}

Some functionally illiterate consumers are willing to seek assistance from store personnel. Some of these consumers prefer to only ask salespeople for help and not fellow shoppers. Others are comfortable asking other shoppers for help or initiating discussions with strangers whom they meet in the store. Some participants ask for help from specific salespeople and subsequently establish relationships with them.

\section{Establish Relationships with Store Personnel}

Some participants have developed relationships with store personnel by revealing their limited literacy skills and regularly seek assistance from staff that they regard as friends. For these participants, store loyalty is based on personalized relationships with specific store employees.

\section{Use Shopping List}

A shopping list may be a practical tool to use in saving money on one's grocery budget each month. Some of the participants have adopted a shopping list as a coping mechanism to help them not to exceed their limited budgets. They usually draw up a list using specific brand names instead of using the product category name. For example, for washing powder they will write down a well-known local brand name such as "OMO" and not the words "washing powder."

\section{Tell Cashier the Total Amount of Money Available}

In order to avoid the embarrassment resulting from a cash shortfall at the checkout counter, some participants tell the cashier the exact amount they have available so that the cashier can ensure that the total of the purchased goods does not exceed this amount.

\section{Give Cashier All Money Available}

Although some of the participants have their doubts about the honesty of cashiers, they still give the cashier all their money hoping that they will receive back the correct change.

\section{Implications of the Findings}

The aforementioned findings regarding the decision-making approaches and coping mechanisms used by functionally illiterate consumers have important theoretical and practical implications for academic researchers and policy makers as well as for marketers and retailers.

\section{Implications for Academic Researchers}

Existing models of consumer decision making are based on implicit behavioral assumptions deemed to reflect the normal sequence that consumers engage in to arrive at a final purchase decision (Schiffman et al., 2011). The typical consumer decision-making model states that consumers are influenced by marketing/ brand information and product attributes when making judgments and choosing among competing products. The findings of this study suggest that, for functionally illiterate consumers, the information search stage is either nonexistent or is limited to a few trusted sources such as friends and family, often occurring after a purchase has been made. These findings imply that existing academic models of consumer decision making may have to be revised to specifically account for the decision-making approaches used by functionally illiterate consumers who constitute a sizable consumer segment in many developing economies.

\section{Implications for Policy Makers}

The fact that research into the marketplace behavior and experiences of the nearly 10 million functionally illiterate consumers in South Africa is nonexistent suggests that existing policies and practices regarding branding, product labeling, pricing, and consumer protection are largely based on the behavior and needs of literate consumers. It would be beneficial if such policies and practices could specifically consider the unique needs of and challenges faced by functionally illiterate consumers. The functionally illiterate participants in this study recounted several negative shopping experiences resulting from the indifference of retailers and, in many cases, the rudeness and lack of assistance from sales staff. This calls for public policy makers to implement policies aimed at protecting these vulnerable individuals. Policy makers are advised to familiarize themselves with the realities faced by functionally illiterate consumers, in order to gain insight into their needs and to be able to protect them more effectively. The findings of this research also suggest that more research has to be done 
to reveal the specific literacy-related shopping challenges faced by functionally illiterate adults in South Africa and to specifically address these challenges in the curricula of adult-learning programs.

\section{Implications for Marketers and Retailers}

Functionally illiterate consumers' use of pictorial thinking, concrete reasoning, and specific coping mechanisms has important implications for the marketers of fast-moving consumer goods as well as for grocery retailers. These findings accentuate that both marketers and retailers should understand the extent of functional illiteracy in their respective customer bases. Marketers should conduct research into the needs of the functionally illiterate segment in relation to their specific brand, so as to appropriately adapt the relevant marketing mix elements.

Retailers should create a friendly shopping environment by sensitizing their staff to the specific needs of and coping mechanisms used by functionally illiterate shoppers. In this way, staff would be able to identify these consumers and offer them the required assistance, without harming their self-esteem.

While the majority of consumers in South Africa are not first-language English speakers, marketing information is primarily communicated to consumers in English. The findings of this study clearly indicate that functionally illiterate consumers often struggle to comprehend information presented in English. This calls for the use of basic English to convey information on product packaging and, where possible, for the inclusion of local African languages as well. This recommendation could also be extended to in-store signage. In addition, illustrating product-attribute information and store signage pictorially could reduce the frustration and anxiety experienced by functionally illiterate shoppers.

The findings further indicate that functionally illiterate consumers are attracted to price deals, but lack the numeracy skills to estimate the actual value of percentage-based price discounts. They also experience difficulties with basic computations, such as totaling the cost of goods purchased. Retailers should, therefore, avoid discounts in percentage form and rather adopt a rounding-off pricing strategy or express price promotions using the actual amount saved and not fraction-off or percentage discounts.

Changes to packaging create confusion and may lead to brand switching when functionally illiterate consumers fail to identify the brand they usually buy. Marketers should aim to maintain the same logo, fonts, and colors on the packages, since these are the features that functionally illiterate consumers use to identify products. When there is a need to change product packaging, the new packaging should be introduced gradually, linking it with the previous package in order to aid product identification. The old packaging could be shown alongside the new packaging for a period to make illiterate consumers aware that the product still exists; otherwise, these consumers may switch to competing brands, thinking that the product is no longer on the market.

Functionally illiterate consumers are clearly loyal to specific brands. Although they learn about new products through promotional activities, they will not easily buy new products. Typically these consumers would try a new product only after it had been recommended by a trusted source. At times, they will try a new product when it is the cheapest available option. In the latter case, these consumers would have used price as a guide to their choice. To encourage new product usage it is not enough to use in-store promotions, such as product sampling. The findings of this study suggest that functionally illiterate consumers might sample the new product but would still proceed to buy their favorite brand. Marketers are, therefore, advised to target the so-called trusted sources (e.g., friends and family members), so that they in turn would recommend the specific new product to illiterate consumers.

\section{LIMITATIONS AND DIRECTIONS FOR FUTURE RESEARCH}

The data for this study were collected through semistructured in-depth interviews conducted with twelve individuals living in the same geographical area. All the normal limitations associated with semistructured in-depth interviews, such as tentative generalizations of findings and a small sample size, therefore apply to this study. Future research could incorporate other data collection methods, such as observation, and also increase the sample size by involving functionally illiterate consumers from other urban and rural communities in South Africa.

Functionally illiterate consumers might not be particularly aware of their coping behaviors or be able to accurately relate their marketplace experiences; hence, one could add value by also observing their shopping behavior. Although the interviews went smoothly, the researcher is functionally literate and, therefore, may have been biased and may not have been able to relate emotionally to the challenges of being functionally illiterate.

The interview guide contained a list of coping mechanisms that were identified from previous studies conducted in the developed world. These were used as a guide to ask participants if they used the same coping strategies. While the current study identified a total of 17 coping mechanisms, it is important to understand the 
underlying situations that give rise to the use of specific coping mechanisms. Future studies could use a different approach by encouraging participants to come up with the specific coping mechanisms they use, without the researchers making suggestions. This could reveal the conditions that encourage participants to use specific coping mechanisms.

Another limitation of this study is that the participants were all enrolled at an adult literacy learning center. Future research could focus on functionally illiterate consumers who are not improving their literacy to determine whether there is any difference in behavior. At a marketing design level, research could be conducted on the actual processing of information written on packaging and labels. Given the fact that most functionally illiterate consumers in South Africa are women, who make purchases on behalf of their families, it is important to assist them in making informed decisions. Exploring the experiences of functionally illiterate consumers in other retail settings and product contexts could also be beneficial. In addition, future research should explore the experiences of these consumers in service contexts. Finally, research could be conducted to compare the decision-making processes and criteria of illiterate consumers with those of literate consumers for the same product category.

\section{ACKNOWLEDGMENT}

We thank Ms. Kelly Summerfield for her assistance in preparing the final version of this article.

\section{REFERENCES}

Adkins, N. R. (2001). Low literate consumers in a literate marketplace: Exploring consumer literacy and its impacts (Doctoral dissertation) Virginia Polytechnic Institute and State University, Blacksburg, VA.

Adkins, N. R., \& Ozanne, J. L. (2005). Critical consumer education: Empowering the low literate consumer. Journal of Macro-marketing, 24(2), 153-162.

Adamowicz, W. A., \& Swaitare, J. (2012). Food choices really habitual? Integrating habits, variety-seeking and compensatory choice in a utility-maximizing framework. Agricultural and Applied Economics Association, 95(1), 17-41.
Crosswaite, I. (2013). Eight megatrends impacting South African consumer behaviour in 2013. Retrieved from http://www.added-value. com/source/2013/05/eight-megatrends-impacting-south-africanconsumer-behaviour-in-2013/\#sthash.ikvtDf3b.dpuf

Erasmus, A. C., Boshoff, E., \& Rousseau, G. G. (2001). Consumer decision-making models within the discipline of consumer science: A critical approach. Journal of Family Ecology and Consumer Sciences, 29, 82-90.

Fuat Firat, A. (2006). Brand literacy: consumer's sense-making of brand management. Advances in Consumer Research, 33, 375-380.

Gau, R., \& Viswanathan, M. (2008). The retail experience for lowliterate consumers. Journal of Research for Consumers, 15, 1-19.

Harrison-Walker, L. J. (1995). The importance of illiteracy to marketing communication. Journal of Consumer Marketing, 12(1), $50-62$.

Jae, H., \& Delvecchio, D. (2004). Decision-making by low literacy consumers in the presence of point-of-purchase information. The Journal of Consumer Affairs, 38(2), 342-354.

Jae, H., \& Viswanathan, M. (2012). Effects of pictorial product-warnings on low-literate consumers. Journal of Business Research, 65, 1674-1682.

Kardes, F. R., Cline, T. W., Askegaard, S., \& Hogg, M. K. (2011). Consumer behaviour: Science and practise. Mason, $\mathrm{OH}$ : Cengage Learning.

Merriam, S. B. (2009). Qualitative research: a guide to design and implementation. San Francisco, CA: Jossey-Bass.

Ozanne, J. L., Adkins, N. R., \& Sandlin, J. A. (2005). Shopping [for] power: How adult literacy learners negotiate the marketplace. Adult Education Quarterly, 55(4), 241-268.

Prinsloo, N., van der Merwe, D., Bosman, M., \& Erasmus, A. (2012). A critical review of the significance of food labelling during consumer decision-making. Journal of Family Ecology and Consumer Sciences, 40, 83-98.

Ringold, D. J. (2005). Vulnerability in the marketplace: Concepts, caveats and possible solutions. Journal of Macro-Marketing, 24(2), 202-214.

Rosa, J. A. (2012). Marketing education for the next four billion: Challenges and innovations. Journal of Marketing Education, 34(1), 44-54.

Schiffman, L. G., Hansen, H., \& Kanuk, L. (2011). Consumer behaviour: A European outlook. New York, NY: Pearson Prentice Hall.

South African Department of Education. (2007). Ministerial committee on literacy: Plan for a literacy mass campaign for South Africa. Pretoria, South Africa: Government Printer.

UNESCO. (2006). Literacy for life: EFA Global monitoring report2006. Paris, France: UNESCO.

Viswanathan, M., Jung, K., Venugopal, S., Minefee, I., \& Jung, I. W. (2014). Subsistence and sustainability: From micro-level behavioral insights to macro-level implications on consumption, conservation, and the environment. Journal of Macromarketing, 34(1), 8-27.

Viswanathan, M., Rosa, J. A., \& Harris, J. E. (2005). Decision-making and coping of functionally illiterate consumers and some implications for marketing management. Journal of Marketing, 69, 15-31.

Wallendorf, M. (2001). Literally literacy. Journal of Consumer Research, 27, 505-511. 
APPENDIX A:

These Six Photographs Show Different Store Scenarios That Were Used as Stimuli During the Semistructured Interviews

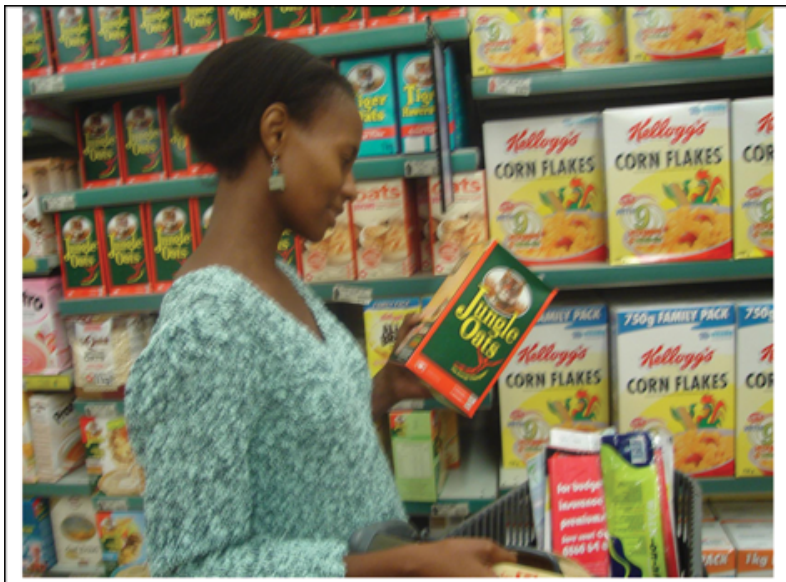

Consumer looking at cereal box

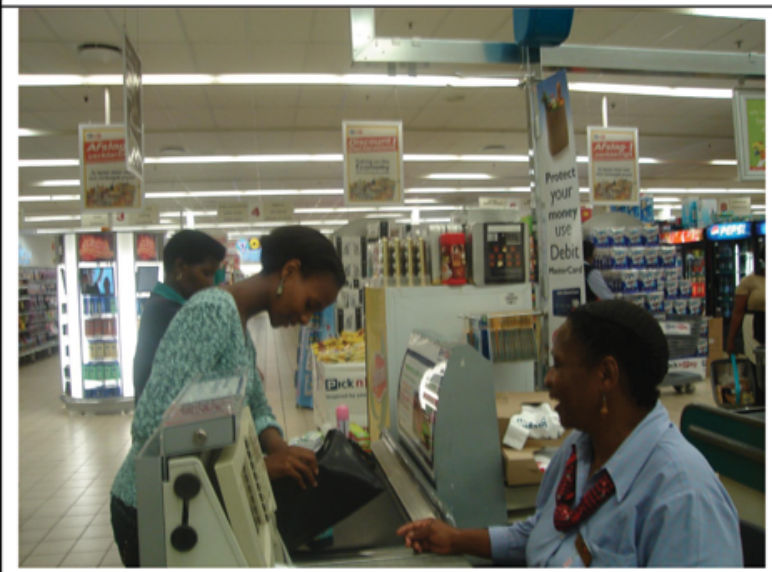

Consumer and cashier at checkout counter

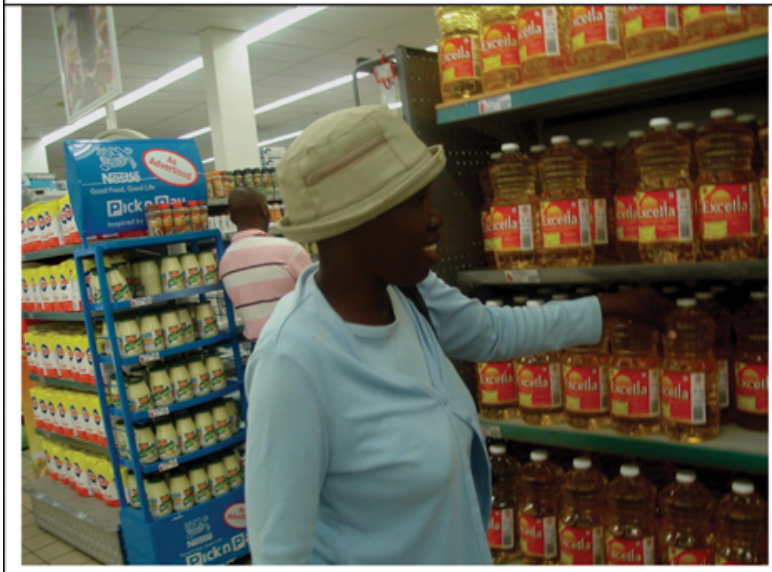

Consumer choosing cooking oil brand

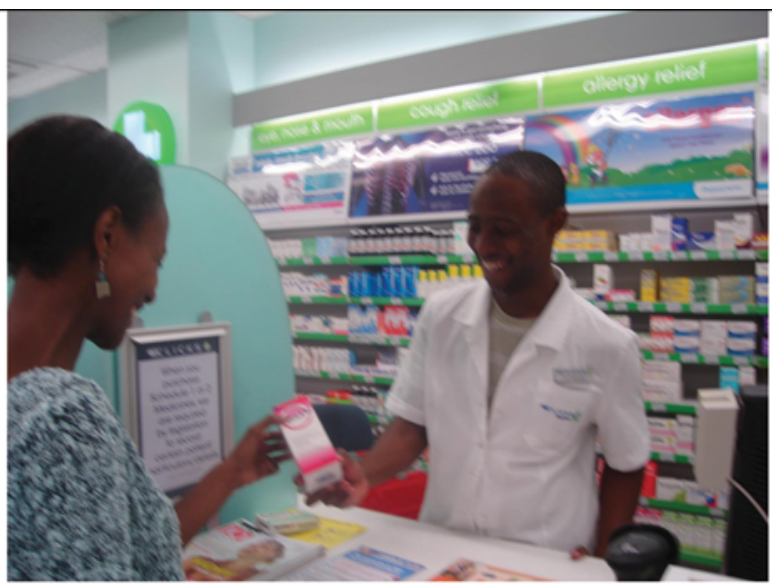

Consumer and pharmacist

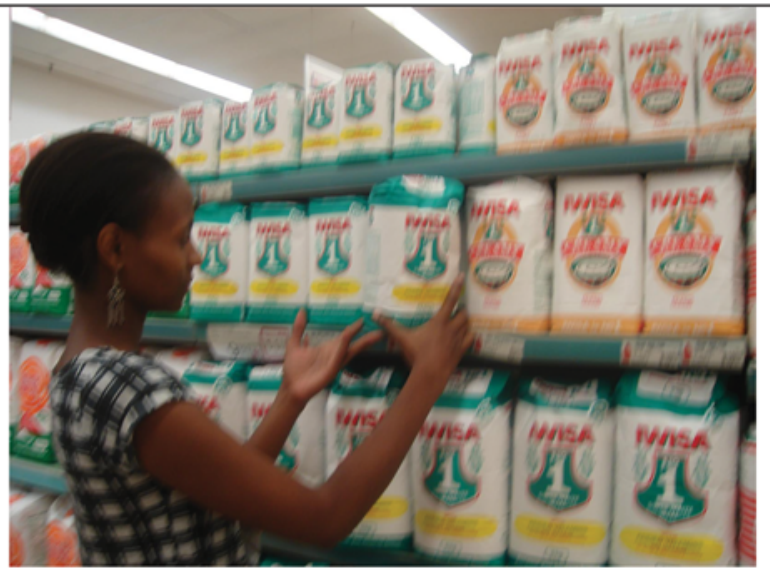

Consumer choosing Mealie Meal brand

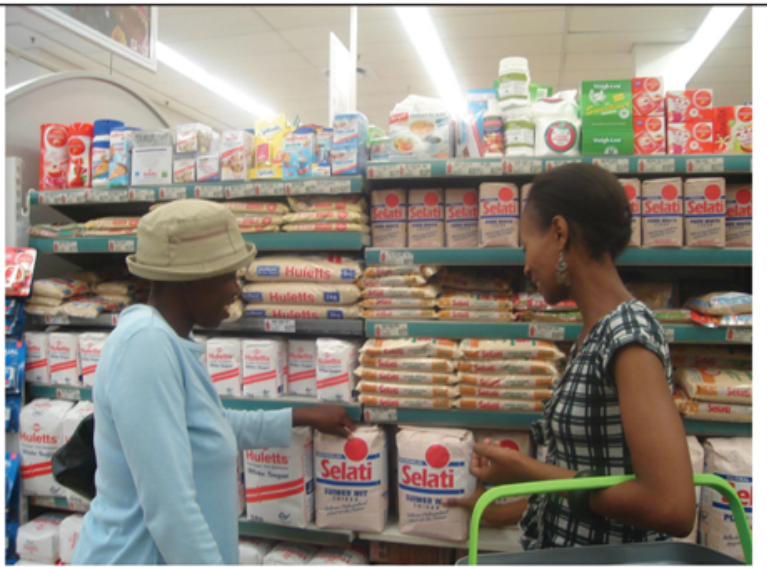

Two consumers discussing products 


\section{APPENDIX B: Interview Guide}

\section{Interview Guide}

\section{Introductory question}

Thank you for your willingness to meet me today. I really need your help on this project. I would like us to start by sharing some basic information with each other. I will start: my name is Sisa Mhlanga I come from Zimbabwe. I am 33 years old and I have a seven year old daughter. Like you I am a student, I am studying at the University of Pretoria. I am working on a project on people's shopping experiences. I would like you to share with me your shopping experiences in a grocery store, to enable me to complete my project so that I can graduate.

1. Question: Tell me about yourself ....

Probes: Age? Do you have family? Children? Where did you go to school? Do you have a job? How long have you been coming to the literacy center?

\section{Context Questions}

2. Question: How do you feel about shopping?

Probes: What makes it easy/hard to shop? How do you do your shopping?

3. Question: Where is your favorite place to shop?

Probes: Why do you like to shop there? How often do you go there? What kinds of things do you buy there? How do you feel shopping there? Why?

Note: Possible probe on salespeople, service, characteristics of retail environment

4. Question: Are there places you do not like to shop at?

Probes: Where are they? Why don't you like to shop there? Do you ever go there? How do you feel after shopping there?

Probes: Do you enjoy shopping? What do you look for when you go to shops?

\section{Projective questions:}

I want to show you a couple of pictures. Please look at each picture and tell me a story about what is going on in the picture.

Show Picture 1: Consumer looking at cereal box

5. Question: What is happening in this picture?

Probes: Can you tell me more about what is going on? What do you this person is feeling? What is she thinking?

Why do you believe they will think/feel like that? What about the other person in the picture?

Picture 2: checkout counter

Picture 3: pharmacy

Picture 4: sugar background

Picture 5: cooking oil

Picture 6: Mealie Meal

\section{Contrast questions}

I want you to think about a time when you were shopping when reading was not a problem.

6. Question: Can you tell me of a time like that?

Probes: What where you shopping/buying? Where were you? Did you have any problems because reading and writing were involved? What did you do?

Note: Other probes on seeking assistance depending on seeking assistance using visuals or other coping mechanisms depending on their answers. 
7. Question: Can you think about a recent time when you were shopping when reading and writing was a problem Probes: What where you shopping/buying? Where were you? Did you have any problems because reading and writing were involved? What did you do?

8. Question: Can you tell me about a good shopping trip Probe: What made it good?

9. Question: What about a bad shopping trip?

Probe: Why was it bad?

\section{Questions on others they know with limited literacy skills}

10. Question: Why did you decide to enroll for this program?

Probes: How do you feel about the help so far? Do you think other people should get help with their reading and writing? Why? If you could talk to someone with reading and writing problems, what would you tell them? Why?

11. Question: I had someone in Pretoria who told me about a restaurant in town that sells stale food to people, labeling them to be stupid!!

Probes: Do you know anyone who has had the same experience?

\section{Structured question on surrogate literacy skills}

12. Question: Other people have told me ways that they would get what they wanted when shopping or buying for each of these ways can you tell me if you use any? If so how often do you use the method?

Note: Pull out form containing Table 20 below and take notes while the respondent is talking. For the ones they use frequently, the interviewer will probe further. For example, if they say that they go to friendly salespeople, interviewer could say, "Where do you find friendly people?

Potential probes: What where you buying? Would you use this at every store or just certain ones? At what times would you use it? Why would you use it? Did it always work?

\section{Structured questions and answer sheet}

13. Remember where items are located in store

14. Look for familiar words

15. Memorize product symbols

16. Shop at the same store

17. Buy the same items every week

18. Look for in-store signs

19. Avoid trying unfamiliar products

20. Shop at stores where you know employees

21. Do you worry about crime/security when shopping

22. Do not shop at places where salespeople are unfriendly

23. Prefer stores that use simple prices

24. Prefer store where sale prices are specified as dollar amounts rather than as a percentage

25. How do you compare brands

26. Go shopping with friends/family

27. Do without items

28. Speak in low voice when asking for help 
29. Tell people I forgot my glasses (hide illiteracy)

30. How to you pay at the checkout counter?

31. What do you feel about new products in the market?

32. What do you like about Shoprite?

33. How do you compare prices with quantity?

34. How do you compare price with quality?

35. What are original brands?

\section{Conclusion}

That concludes what I wanted to talk with you about. Thank you once more for taking your time to talk with me today. Do you have any questions for me? If I have any other questions when I am preparing my report, can I call you? 